\title{
Dross Formation in Aluminum Melts During the Charging of Beverage Can Scrap Bales with Different Densities Using Various Thermal Pretreatments
}

\author{
JAN STEGLICH $\odot,{ }^{1,3}$ BERND FRIEDRICH, ${ }^{2}$ and MARCEL ROSEFORT ${ }^{1}$ \\ 1.-TRIMET Aluminium SE, Aluminiumallee 1, 45356 Essen, Germany. 2.-IME Process \\ Metallurgy and Metal Recycling, RWTH Aachen University, Intzestr. 3, 52056 Aachen, Germany. \\ 3.—e-mail: jan.steglich@trimet.de
}

\begin{abstract}
Herein, dross formation $(D)$ in used beverage can (UBC) scrap bales was investigated in laboratory-scale experiments to understand the reactions of solid can coating residues with aluminum melts. The experimental conditions were chosen according to a multi-chamber furnaces process, in which thermal pretreatment and submerged melting of the scrap bales are combined. The thermal pretreatment results show that the supply of oxygen should be continuously adjusted to meet the oxygen demand of UBC scrap bales for thermolysis. Moreover, it is necessary to maintain the UBC scrap bales at an effective material temperature of $550-570^{\circ} \mathrm{C}$ for at least $30 \mathrm{~min}$. It is shown that adhering carbon-containing pyrolysis char and oxidized can sheet surfaces decrease the coalescence of molten scrap, resulting in dross with a high metal fraction. Further melting experiments with UBC scrap bales of different densities $(\rho)$ show that by lowering the $\rho$, the dross formation reduces.
\end{abstract}

\section{INTRODUCTION AND MOTIVATION}

Aluminum beverage cans are widely used, and the can market is continuously growing. After the use and disposal of these cans, the valuable aluminum metal must be recycled to produce new cans to satisfy the requirements of an eco-friendly circular economy. The metallurgical recycling of used beverage can (UBC) scrap is a combined process of thermal pretreatment used to remove the can coating and melting. The melting of scrap still poses a challenge to aluminum recyclers as it leads to metal loss and undesirable dross formation $(D)$. Open questions are how the organic content, coating residues, and UBC scrap bale density $(\rho)$ affect $D$.

As the dross formation reactions are quite complex, this investigation focuses only on the can coating and its residues in UBC scrap bales after pretreatment. The influence of oxygen in the common furnace atmosphere was excluded by performing the laboratory melting experiments under an inert atmosphere.

(Received April 14, 2020; accepted June 30, 2020; published online July 28, 2020)

\section{LITERATURE REVIEW}

\section{Can Coating Removal and Residue}

Waterborne epoxy, polyester, and acrylic polymer resins are widely used as beverage can coatings. Bisphenol-a-diglycidyl ether (BADGE)-based epoxy resins are examples of the commonly used coatings in the can industry. The curing temperature of waterborne resins is in the range of $150-200^{\circ} \mathrm{C}$ depending on the resin-cure system and time. ${ }^{1,2}$ When the curing temperature of a thermosetting polymer exceeds this range, the cross-linked polymer network starts to degrade at the crosslinking bonds. ${ }^{3}$ The decomposition starts with degassing and the formation of pores in the coating. Inorganic pigments and fillers are retained as they do not form volatile products. At elevated temperatures between $300^{\circ} \mathrm{C}$ and $400^{\circ} \mathrm{C}$, different reaction products are formed depending on the oxygen concentration in the pretreatment atmosphere. ${ }^{4}$ In industrial reverberatory furnaces, the ratio of available oxygen and required oxygen for stoichiometric combustion is described by the lambda ratio $(\lambda)$, which is calculated according to Eq. 1: ${ }^{5}$ 


$$
\lambda=\frac{\text { available oxygen }}{\text { stoichiometric required oxygen }}
$$

The amount of oxygen calculated using $\lambda$ is transferred to the thermal pretreatment system and used to describe the total oxygen availability in a reactor vessel with respect to the oxygen demand of the can coating. The ratio, $\lambda$, has significant effects on coating removal and residues, which are summarized in Table I.

Isothermal annealing experiments by Ref. 3 show that thermolysis conditions, i.e., $500-600^{\circ} \mathrm{C}$ temperature and an oxygen atmosphere, are necessary to successfully remove BADGE-based can coatings. The pyrolysis of a similar coating leads to the formation of adhering carbon coating char on the can sheets. ${ }^{7}$

\section{Dross Formation $D$ and Can Alloy Oxidation}

$D$ is attributed to the oxidation of metals and inclusion of liquid aluminum alloys in corresponding oxides. The oxidized metal cannot be recovered in the current industrial processes and is defined as metal loss, whereas the trapped alloy can be recovered by dross processing. ${ }^{8}$ The metal oxidation of UBCs starts during thermal pretreatment after the coating is partially removed. Aluminum beverage cans are produced from EN AW-5182 can end sheets and EN AW-3104 can body sheets or similar alloys. ${ }^{9}$ The major alloying elements are $\mathrm{Al}, \mathrm{Mg}$, and $\mathrm{Mn}$. It is generally known that $\mathrm{Mg}$ increases the oxidation rate of aluminum alloys because of the formation of $\mathrm{Al}_{2} \mathrm{MgO}_{3}$ and $\mathrm{MgO}$ instead of just $\mathrm{Al}_{2} \mathrm{O}_{3}$ as in the case of pure aluminum. ${ }^{9,10}$ Annealing experiments with uncoated can end sheets show that the end sheets oxidize significantly faster (within 7-10 min above $570^{\circ} \mathrm{C}$, but not at $550^{\circ} \mathrm{C}$ ) than the can body sheets. 9

Once the metal surface is oxidized, the coalescence during melting is impeded, and dross is formed. Submerged melting is necessary to limit the exposure of the metal surface to the hot furnace atmosphere. ${ }^{8,9}$ Experiments by Rossel ${ }^{11}$ show that increasing the specific surface area of scrap by reducing the sheet thickness directly leads to increased $D$.

\section{EXPERIMENTAL PROCEDURES}

\section{Material Description}

Melting experiments were performed with commercial UBC scrap bales to obtain $D$ results using industrially relevant materials. All UBC scrap bales had the initial dimensions of approximately $400 \mathrm{~mm} \times 300 \mathrm{~mm}$ and a variable height, depending on their degree of compaction. A description of the various properties and impurities of UBC scrap bales is provided in Table II.

The average oxygen and carbon concentrations in the initial UBC scrap bales were measured by drilling out 12-g chips out of each scrap type and analyzing them by the carrier gas method using the LECO TC600 and LECO CS844 instruments, respectively. Herein, nine spot samples of each scrap type were analyzed to estimate the inhomogeneity. UBC $\mathrm{C}$ was compacted into three samples of different $\rho$, i.e., $\mathrm{C} 1$ dense $\left(1110 \mathrm{~kg} / \mathrm{m}^{3}\right), \mathrm{C} 2$ medium $\left(808 \mathrm{~kg} / \mathrm{m}^{3}\right)$, and C3 low $\left(685 \mathrm{~kg} / \mathrm{m}^{3}\right)$, in an industrial stamping press.

\section{Thermal Pretreatment}

UBC A, B, and $\mathrm{C}$ were cut into sections with a thickness of $40-60 \mathrm{~mm}$, height of ca. $300 \mathrm{~mm}$, and mass of $1095 \pm 127 \mathrm{~g}$. The thermal pretreatment of UBC sections was performed in an airtight steel cylinder (height: $445 \mathrm{~mm}$; diameter: $260 \mathrm{~mm}$ ) with purge gas and off-gas connections in a resistanceheated furnace. Argon, argon with 4 vol.\% $\mathrm{O}_{2}$, and air were used as purge gases at atmospheric pressure and a constant gas flow rate of $10 \mathrm{l} / \mathrm{min}$. The UBC slices were charged before starting the procedure and removed after cooling to maintain a controlled atmosphere during pretreatment. The resistance heating resulted in an average heating ramp of $5^{\circ} \mathrm{C} / \mathrm{min}$ and a plateau at the target temperature of $450 \pm 5^{\circ} \mathrm{C}$ or $550 \pm 5^{\circ} \mathrm{C}$. The reactor temperature was measured using an internal thermocouple. The target temperature was held for $30 \pm 5$ min before cooling down the samples. Every experiment was repeated three times to generate enough mass for subsequent melting.

Pretreatment conditions were chosen to represent the pyrolysis and thermolysis conditions with two different target temperatures. The low thickness of the UBC slices and the low heating rate led to a homogeneous temperature distribution in the

Table I. Definition of $\lambda$ for different thermal pretreatments and the resulting reaction products

Idealized reaction products

\begin{tabular}{|c|c|c|c|}
\hline Pretreatment condition & Lambda ratio5 & Gaseous6 & Solid4 \\
\hline $\begin{array}{l}\text { Combustion, exothermic } \\
\text { Thermolysis, endothermic } \\
\text { Pyrolysis, endothermic }\end{array}$ & $\begin{array}{c}\lambda \geq 1 \\
0<\lambda \leq 1 \\
\lambda=0\end{array}$ & $\begin{array}{c}\mathrm{CO}_{2} \text { and } \mathrm{H}_{2} \mathrm{O} \\
\mathrm{CO}, \mathrm{C}_{\mathrm{x}} \mathrm{H}_{\mathrm{y}}, \mathrm{H}_{2} \mathrm{O} \text {, and } \mathrm{CO}_{2} \\
\mathrm{C}_{\mathrm{x}} \mathrm{H}_{\mathrm{y}}\end{array}$ & $\begin{array}{l}\text { Metal oxides and inorganic pigments } \\
\text { Inorganic pigments } \\
\text { Inorganic pigments and solid carbon residue }\end{array}$ \\
\hline
\end{tabular}


Table II. Properties and impurities of UBC scrap bales

\begin{tabular}{|c|c|c|c|c|c|}
\hline Property & Unit & UBC A & UBC B & UBC C (1-3) & Analysis method \\
\hline Main impurity & - & Coating & Coating, plastic, iron, copper & Coating, plastic & Visual \\
\hline Density & $\mathrm{kg} / \mathrm{m}^{3}$ & 450 & 910 & 1110,808, and 685 & Weighing \\
\hline Volatile organic & wt.\% & $2.8 \pm 0,3$ & $8.4 \pm 4.0$ & $10.0 \pm 2.6$ & Annealing at $450-550^{\circ} \mathrm{C}$ \\
\hline Moisture & wt.\% & $0.9 \pm 0,7$ & $1.7 \pm 1.1$ & $0.9 \pm 0.7$ & Drying at $105^{\circ} \mathrm{C}$ \\
\hline Porosity & $\%$ & 83 & 66 & 59,70 , and 75 & Measuring \\
\hline
\end{tabular}

samples, assumed to be equal to the reactor temperature.

\section{Melting of UBC Scrap Bales}

After pretreatment, the UBC slices were carefully cut into $100 \pm 1 \mathrm{~g}$ cubes such that the original pore structure of the initial bales was retained. Samples were also cut out of the initial UBC bales for reference experiments without heat treatment. The experiments were first repeated three times to measure the dross and metal yield $(\eta)$ and then a fourth time to analyze the solidified dross/metal interface.

The UBC samples were submerged into $1000 \pm 5 \mathrm{~g}$ pure aluminum heated in a $\mathrm{SiO}_{2} / \mathrm{Al}_{2} \mathrm{O}_{3}$ crucible by an induction furnace to $750^{\circ} \mathrm{C}$ under an argon atmosphere to exclude reactions with oxygen. A steel cylinder with a removable lid and argon injection was placed on the crucible before starting the melting process. The lid was designed to carry a UBC sample carrier to push the sample into the melt or a dross skimming tool for a uniform skimming procedure. The setup is schematically shown in Ref. 7. After melting the scrap and an additional 30 -min reaction (35 min total including melting), the dross was skimmed and cooled in argon. Additional experiments in ambient air were performed without argon.

The UBC melting experiments were assessed by $D$, the formation of non-metallic products $N M P$, which can also be referred to as system metal loss, and the metal yield $\eta$. $D$ is calculated using Eq. 2 by setting the dross mass into relation with the dry scrap mass, which is also referred to as gross melt loss. ${ }^{13}$ As the exact amount of metal in a commercial UBC scrap sample is unknown before any treatment, a true melt loss cannot be calculated. Even though the true melts loss would be more precise to describe the recovered aluminum metal, the $D$ is more practical and widely used by the aluminum recycling industry. ${ }^{13}$ The NMP was determined by remelting one-third of the dross in an equimolar salt flux of $\mathrm{NaCl}: \mathrm{KCl}$ with 5 wt. $\%$ cryolite $\left(\mathrm{Na}_{3} \mathrm{AlF}_{6}\right)$ and subsequently weighing the metal and non-metallic contents. The three criteria are calculated according to Eqs. 2-4.

$$
\text { Dross formation } D \text { in } \%=\frac{\text { dross mass }}{\text { dry scrap mass }} \times 100
$$

$$
\text { NMP in } \%=\frac{\text { dross mass }- \text { metal mass in dross }}{\text { dross mass }} \times 100
$$

$$
\begin{aligned}
& \text { Metalyield } \eta \text { in } \%= \\
& \left(\frac{\text { metal mass in dross }+ \text { recovered metal mass }}{\text { dry scrap mass }}\right) \times 100
\end{aligned}
$$

Note that the $\eta$ is the sum of the metal reclaimed by UBC melting and the metal fraction recovered of dross remelting $\left(m_{\mathrm{M}}\right)$. Therefore, it specifies the aluminum metal that has been recovered by both processes. The metal yield is unequal to the metal recovery, setting the recovered aluminum mass into relation just with the metal input.

\section{RESULTS}

\section{Thermal Pretreatment}

The main influence of thermal pretreatment was the formation of an adhering carbon-containing coating residue on the can sheets by pyrolysis when argon was used $(\lambda=0)$. This residue was visible on all scrap types at varying quantities depending on the initial organic content. Thermolysis under argon with 4 vol. $\% \mathrm{O}_{2}$ atmosphere $(0<\lambda<1)$ leads to less coating residue; however, the coating is still not completely removed. Similar results were obtained for the decoating experiments performed at $450^{\circ} \mathrm{C}$. Therefore, all other decoating experiments were performed at a $550^{\circ} \mathrm{C}$ material temperature. The incomplete coating removal was evaluated by comparing the remaining carbon and oxygen concentrations of the scrap with the respective initial concentrations.

The use of an air atmosphere $(\lambda \geq 1)$ led to an almost complete decoating of UBC A with only very little oxidation, whereas severe oxidation of UBC B under comparable process conditions was observed. Further investigations showed that a higher organic content (UBC A: $2.8 \pm 0.3 \%$ versus UBC B $8.4 \pm 4.0 \%$ ) triggered an exothermic combustion 
reaction in the pretreatment reactor, resulting in extensive metal oxidation and dross formation in subsequent melting experiments. After this observation, the oxygen supply during de-coating was adjusted, and the experiments were repeated with UBC C.

The oxygen demand of UBC $\mathrm{C}$ was roughly calculated using the organic mass of the samples, the molecular formula of epoxy, polyester, and PET monomers, and a simplified combustion calculation for thermolysis and combustion conditions. The calculation yielded the oxygen demand of 5-8 $\mathrm{mol}$ $\mathrm{O}_{2}$ per $\mathrm{kg} U B C$ scrap, which was supplied by ambient air into the reactor at $10 \mathrm{l} / \mathrm{min}$ over the reaction time of 50-60 min, following the ideal gas law. Herein, the balance of oxygen demand and supply over the process time is defined as stoichiometric thermolysis. These conditions led to the best decoating while simultaneously reducing the metal oxidation.

Note that the stoichiometric thermolysis condition $(\lambda \approx 1)$ was only fulfilled over the thermal reaction time of 50-60 min. The limited but continuous oxygen supply resulted in substoichiometric conditions in the reactor as most of the oxygen reacted with organics. Supplying all the oxygen at once into the heated reactor would result in an exothermic combustion reaction and metal loss. This approximation should be further developed in future research.

It is summarized that industrial thermal pretreatment should not be operated under static process conditions; however, the oxygen supply should be continuously adjusted to meet the oxygen demand of the scrap. Therefore, the organic content of the scrap in the reactor should be determined. Additionally, the treatment time needs to be adjusted according to the $\rho$, gas flow, and degradation kinetics of different organic contaminants for successful decoating.

\section{Impact of $\rho$ on $D$}

The $D$ results of UBC C1-C3 are plotted versus their $\rho$ in Fig. 1. The results are displayed in groups based on the pretreatment. A linear best-fit line was plotted through the results, and the correlation coefficient $r_{x y}$ used to rate how well the variables $\rho$ and $D$ fit to the trend. Finally, the $D$ results of UBC $\mathrm{A}$ and $\mathrm{B}$ were added.

The results in Fig. 1 highlight that pyrolysis leads to a constantly high $D$ over the entire range of $\rho$. As previously shown, pyrolysis leads to a film of adhering carbon-containing coating residue, lowering the coalescence of molten sheets in the metal. Therefore, $D$ is constant with respect to the can sheet surface area. Compared to the case of pyrolyzed scrap, $D$ in the initial beverage can increases with $\rho$.
The comparison results of different scrap types with $\rho<750 \mathrm{~kg} / \mathrm{m}^{3}$ in Fig. 1 obviously show that the stoichiometric thermolysis lowered the $D$ to a minimum value as compared to that of the initial scrap. Based on the previously measured carbon and oxygen concentrations in the scrap, a lower $\rho$ promotes the removal of organics and the effectiveness of thermal pretreatment. As a result, lowdensity scrap has fewer contaminants and results in less $D$. A lower $\rho$ also lowers $D$ in the raw scrap without thermal pretreatment; however, the slope of the linear best-fit line is not very steep. As the argon atmosphere prevented the combustion of organic contaminants during melting, the organics were removed as volatiles.

\section{$\eta$ of UBC scrap bales}

The $\eta$ of UBC A and B was not improved by the applied thermal pretreatment. Unfortunately, the melting of the initial scrap samples resulted in the highest $\eta$. Initially, the static process parameters were not adjusted according to the scrap bales and led to incomplete pretreatment or metal oxidation. Subsequently, the protective argon atmosphere used in the melting experiments prevented metal loss in the untreated scrap. This unexpected result is discussed in "Understanding the Organic Content as a Heating Value" section.

For UBC C, stoichiometric thermolysis conditions were applied. The $\eta$ results are shown in Fig. 2. After adjustment, the thermolysis pretreatment conditions simultaneously maximized the $\eta$ of the scrap and minimized $D$ (see Fig. 2). The theoretical $\eta$ of UBC C was $87.4 \%$ based on the measured organic content of up to $12.6 \%$. This $\eta$ was achieved in one of the samples with a medium $\rho$ after thermolysis at $550^{\circ} \mathrm{C}$ in air (thermo mid). Even though the theoretical metal yield cannot be met in industrial processes, the results show that thermolysis maximizes the performance of submerged scrap melting and subsequent dross processing.

An increasing $\eta$ trend with decreasing $\rho$ is also observed in Fig. 2 for all pretreatment conditions. If UBCs have to be recycled as bales, the $\rho$ should be as low as possible to minimize metal loss and as high as required for economic transportation and storage.

\section{DISCUSSION}

\section{Dross Formation Mechanisms}

In an industrial multi-chamber furnace, scrap bales are pushed into the melt after thermal pretreatment. All remaining coating residues are submerged with the scrap into the melt. In contrast to a reverberatory hearth furnace, the scrap does not melt in the hot burner atmosphere, but is submerged in the melt. 

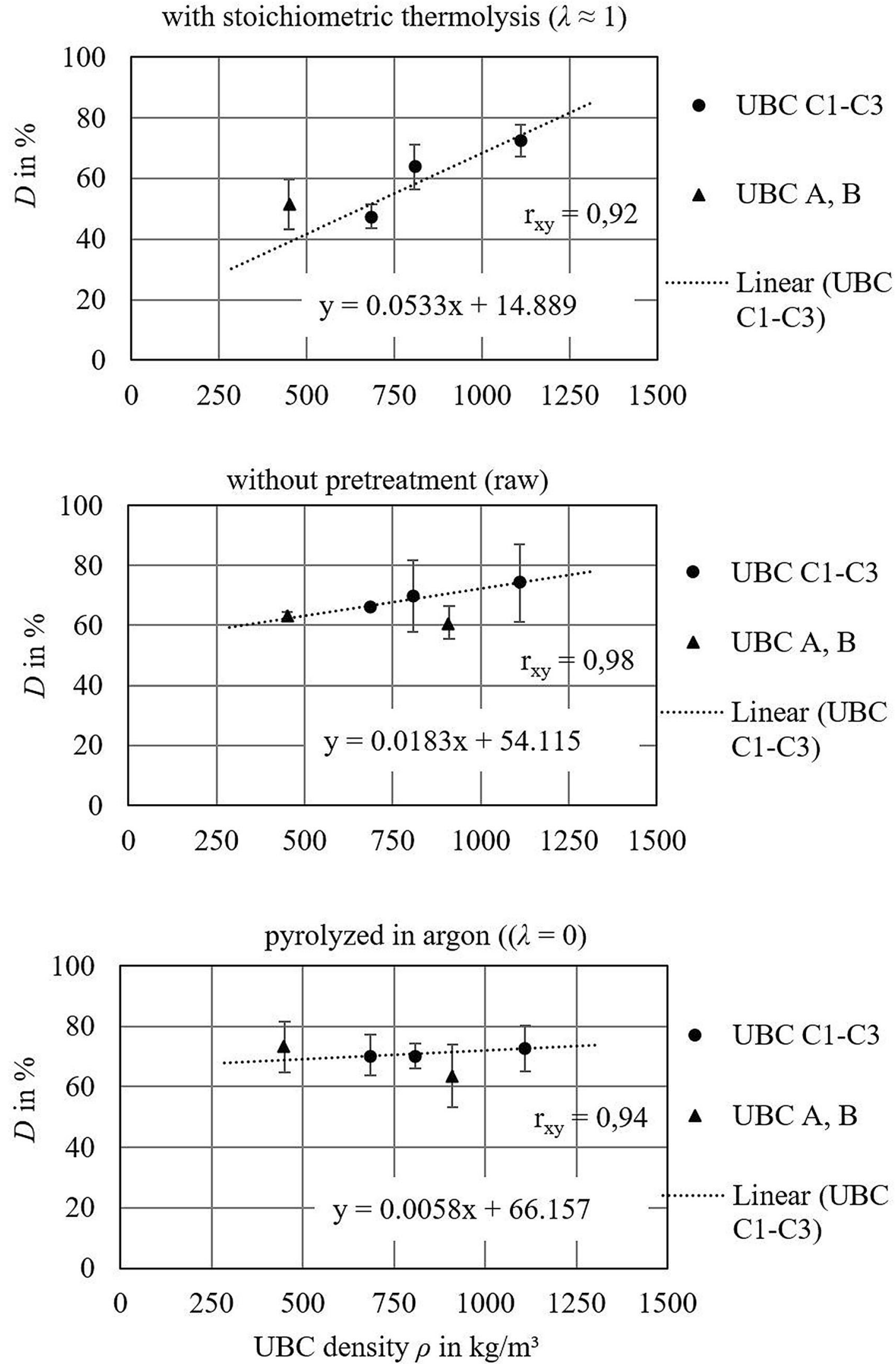

Fig. 1. Dross formation $(D)$ results of UBC as well as comparison of the linear dependence of scrap density $\rho$ with $D$ and the corresponding correlation coefficient $r_{x y}$. 


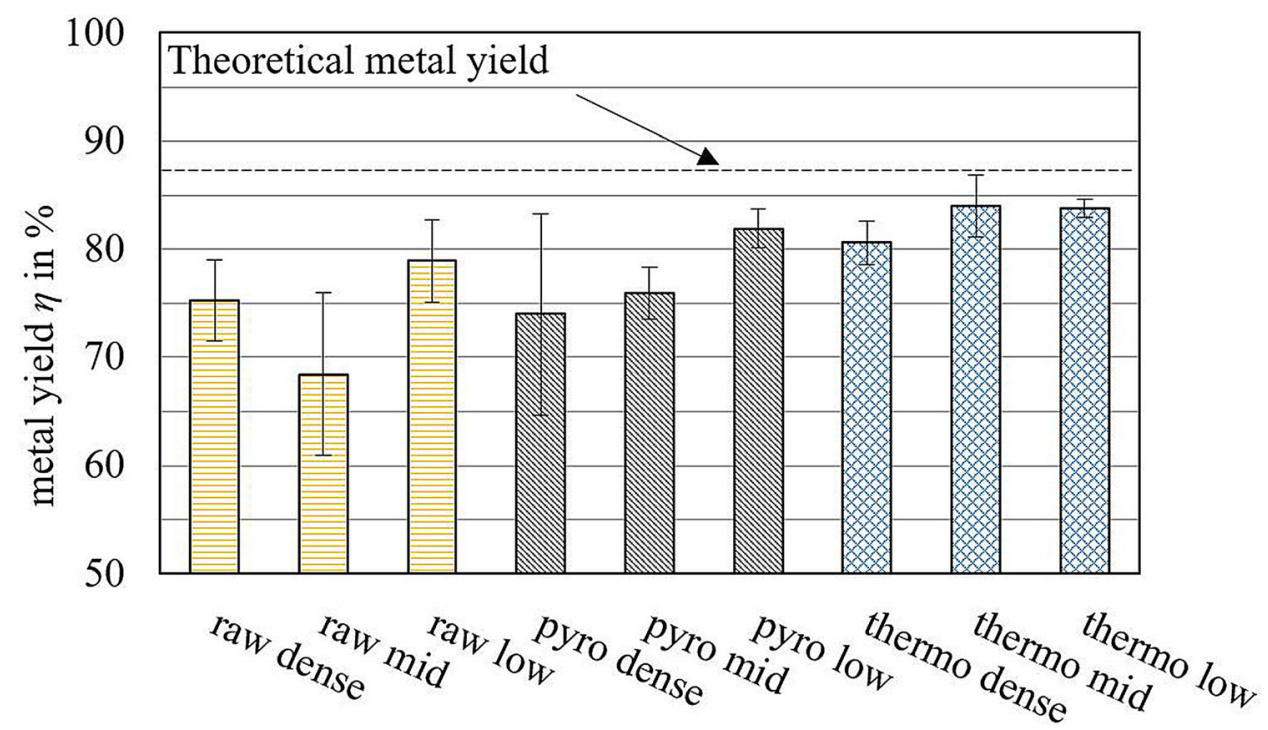

Fig. 2. Metal yield $\eta$ of UBC C with the bale densities of $1110 \mathrm{~kg} / \mathrm{m}^{3}$ (dense), $808 \mathrm{~kg} / \mathrm{m}^{3}$ (mid), and $685 \mathrm{~kg} / \mathrm{m}^{3}$ (low), without pretreatment (raw), after pyrolysis in argon at $550^{\circ} \mathrm{C}$ (pyro), and stoichiometric thermolysis in air at $550^{\circ} \mathrm{C}$ (thermo).

The melting of untreated UBC scrap bales with coating led to large amounts of dross. This dross had a high metal content with honey-like viscosity. Even though there were no solid coating residues from pretreatment in the initial scrap, the metal was trapped in oxide films, generated by gaseous decomposition products of the organic contamination. Melting of scrap bales with pyrolysis pretreatment increased the $D$ compared to that of the untreated material. This is caused by the adhering of pyrolyzed coating char residue to the metal sheets. Consequently, pyrolysis leads to reinforced composite "bi-films", 8 supporting the structure of scrap bales. Melting of scrap bales after adjusting the thermolysis pretreatment conditions minimized the
$D$ and maximized the $\eta$. Only fractured oxide films of beverage can sheets were detectable as nonmetallic inclusions in the dross layer, showing that coalescence was achieved. The dross formation mechanisms are summarized in Fig. 3 and explained in further detail in Ref. 7.

\section{Dross Formation by Metal Inclusions Caused by Solid Coating Residues}

The influence of the above described solid coating residues and oxide films on dross formation, caused by the thermal history of the scrap, is quantified in Fig. 4. The molten metal, trapped in the solidified

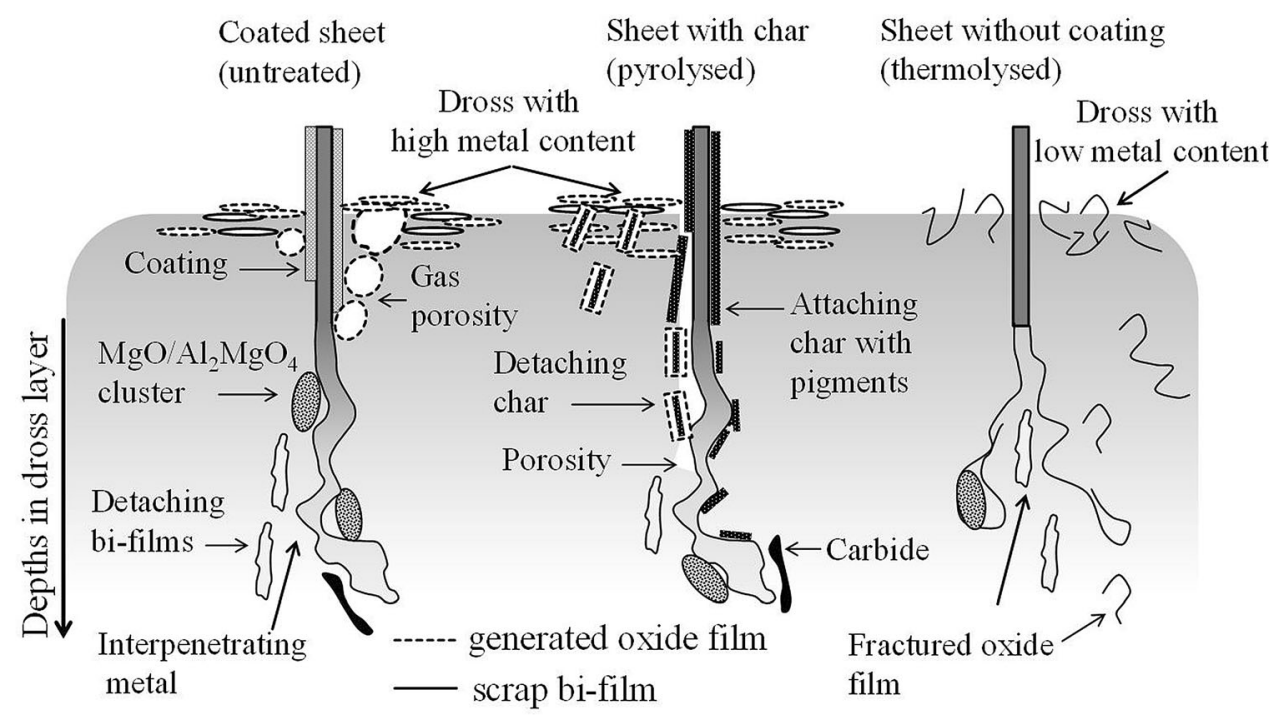

Fig. 3. Proposed dross formation mechanisms of coated can sheets with and without thermal pretreatment based on metallographic results. Reprinted with permission from Ref. 7. 


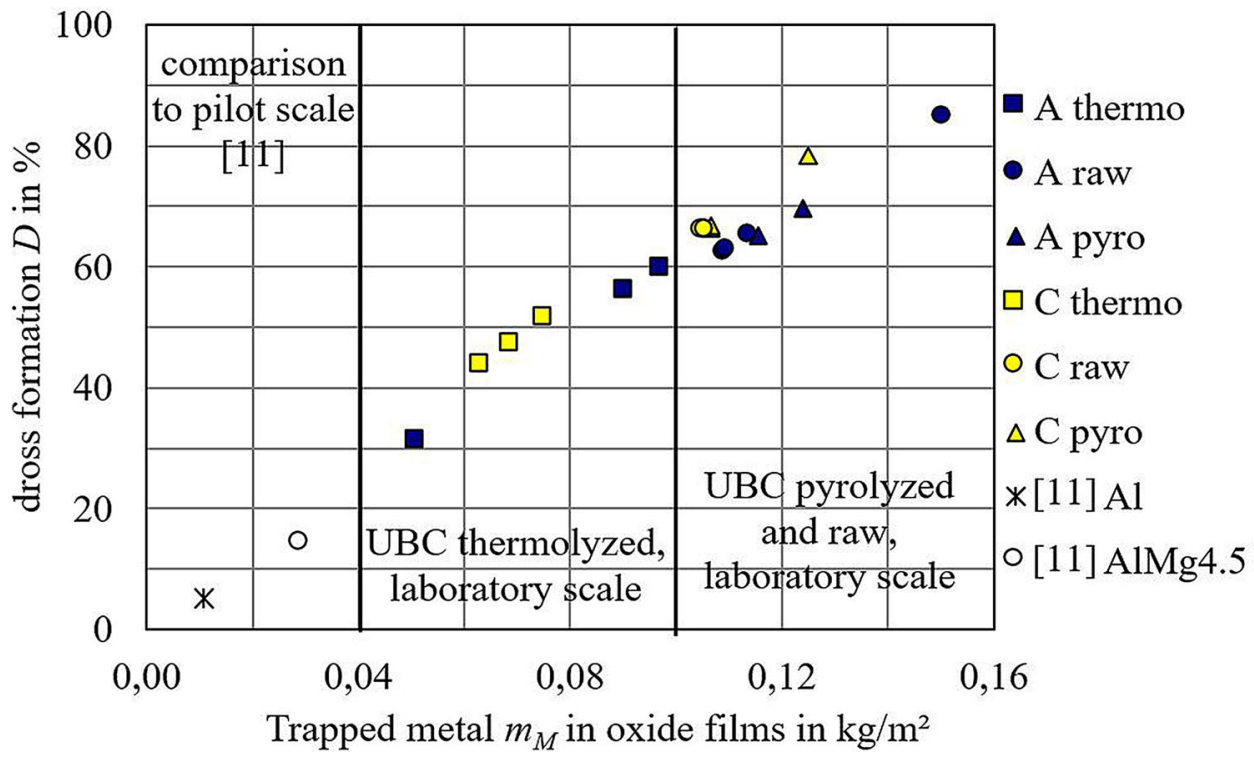

Fig. 4. Impact of trapped metal $m_{\mathrm{M}}$ in oxide films on the dross formation $D$ of UBC bale scrap compared to data of Ref. 11 determined via pilotscale experiments with sheet scrap.

dross, was recovered by remelting under salt flux. This metal fraction $m_{M}$ is set with respect to the can sheet surface area and plotted on the x-axis. The according $D$ results of UBC A and C are plotted over the $\mathrm{y}$-axis as they have a low $\rho$, whose influence can be excluded here. The UBC masses and surface areas were comparable and constant in all the melting experiments with $m_{\mathrm{UBC}}=0.1 \mathrm{~kg}$ and $A=0.5 \mathrm{~m}^{2}$. In addition, these values are compared with the $D$ results of Ref. ${ }^{11}$, which were conducted on a pilot scale with $200 \mathrm{~kg}$ uncoated $\mathrm{Al}$ and AlMg4.5 sheets. The scrap had a total surface area of $973 \mathrm{~m}^{2}$ and was melted in a gas-fired reverberatory furnace. The comparison in Fig. 4 shows a correlation between the $m_{M}$ in oxide films and $D$. In these laboratory-scale experiments, the scrap bales were molten under inert gas, limiting molten metal oxidation. The $D$ is therefore mainly influenced by trapped metal in the carbon or oxide-reinforced can sheet oxide films.

From Fig. 4 it is summarized that pyrolyzed UBC produces comparable or even more dross than the initial scrap without any decoating. The carbon-containing coating residue on the can sheets was found in the solidified dross even after a 35-min reaction in the liquid melt at $750^{\circ} \mathrm{C}$. Metallographic investigations of the dross metal interface revealed that the carbon layer effectively prevented metal coalescence, trapping $70-90 \%$ of the can alloy in the dross layer. Note that the laboratory-scale $D$ results are not directly transferable to the industrial scale. Upscaling effects, such as the metallostatic pressure of liquid aluminum in the dross layer of industrial furnaces, led to less $m_{M}$ and therefore less dross.

\section{Understanding the Organic Content as a Heating Value}

The melting of UBC A and B without pretreatment resulted in an approximately $60 \%$ dross and $90 \% \eta$ although the organic contaminants in UBC B were three times those in UBC A. Contrary to the case of industrial furnaces, the laboratory melting experiments were conducted in argon. It is hypothesized that an inert gas effectively prevents the reaction of organic content. To verify this hypothesis, melting experiments were repeated in air instead of argon with all three UBC types. The impact of organic content on $D$ and $\eta$ was then compared with that assessed by previous experiments in argon.

Figure 5 compares the $D$ and $\eta$ of UBC scrap bales plotted against their organic contents. The $r_{x y}$ was also used to evaluate the fit of the variables to a linear trend. It is confirmed that melting in air results in a functional correlation between $D$ and the organic content, whereas this is not the case for argon. Melting in air resulted in visually observable combustion of the organic content and immediate metal oxidation. Metal oxidation leads to increased $D$ and reduced $\eta$.

The $\eta$ obtained by melting the UBC scrap bales in argon and air is also compared in Fig. 5. As expected, melting in air leads to a lower $\eta$ because of the uncontrolled combustion of organics, creating temperature peaks at the can sheet and resulting in metal loss. The $r_{x y}$ shows a smaller difference than previously as the argon atmosphere does not prevent reactions of the liquid melt with gaseous decomposition products of the organic contaminants. 

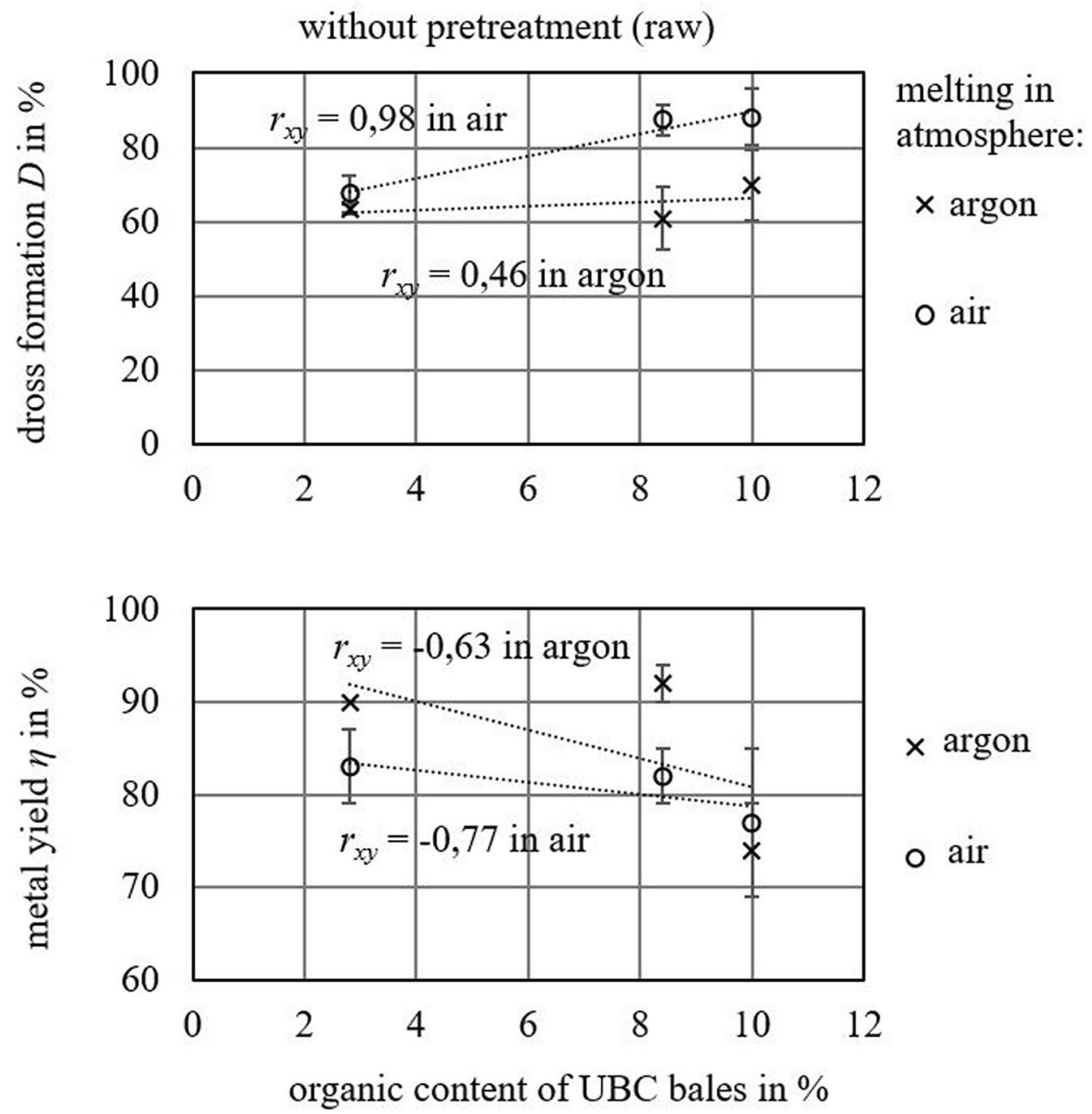

Fig. 5. Comparison between $D$ and $\eta$ of UBC A, B, and C2 by submerged melting in argon and air with the correlation coefficient $r_{x y}$.

Consequently, the relationship between the organic content and $D$ can be understood via the calorific value $\left(H_{i}\right)$ of organics under these experimental conditions. Herein, the $H_{i}$ in combination with the oxygen-containing furnace atmosphere led to the uncontrolled combustion of scrap bales.

Due to the different behaviors of scrap bales under similar process conditions, the organic removal should be distinguished in the cases shown in Fig. 6. During pretreatment, UBC B was burning in over stoichiometric atmosphere, while UBC A had a too low carbon content (or $\mathrm{Hi}$ ) to ignite. It is decisive that the Hi of organic contaminants (mixture of polyethylene/polyester) is similar to that of fuel oil with $H_{i}=10 \mathrm{kWh} / \mathrm{kg}$. ${ }^{12}$ The cases in Fig. 6 show the different behaviors of UBC scrap bales and conditions to avoid uncontrolled combustion.

Regarding thermal decoating, $H_{i}$ should be removed without exothermic combustion, which is achieved by limiting the oxygen availability to a stoichiometric ratio over the pretreatment time. For an industrial process, it is necessary to measure the organic load, calculate the oxygen demand, and supply required oxygen during the process. This appears quite challenging for state-of-the-art process-control techniques, thus requiring further improvements.

\section{CONCLUSION}

The $D$ and $\eta$ of UBC recycling are the result of the two-step process of thermal decoating and submerged melting. The results show that the thermal pretreatment of UBC scrap bales effectively reduces $D$ if stoichiometric thermolysis is applied for a holding time long enough to achieve a material temperature of $550-570^{\circ} \mathrm{C}$ for at least $30 \mathrm{~min}$. The use of shredded or loose UBC is recommended as a larger specific surface area will promote heat transport to the material and thermolysis gas transport out of the scrap. The laboratory results indicate that UBC scrap bales with a low $\rho\left(<450 \mathrm{~kg} / \mathrm{m}^{3}\right)$ should be used because a higher $\rho$ negatively influences mass loss and $D$. This result needs to be verified in industrial-scale furnaces with submerged scrap melting. 


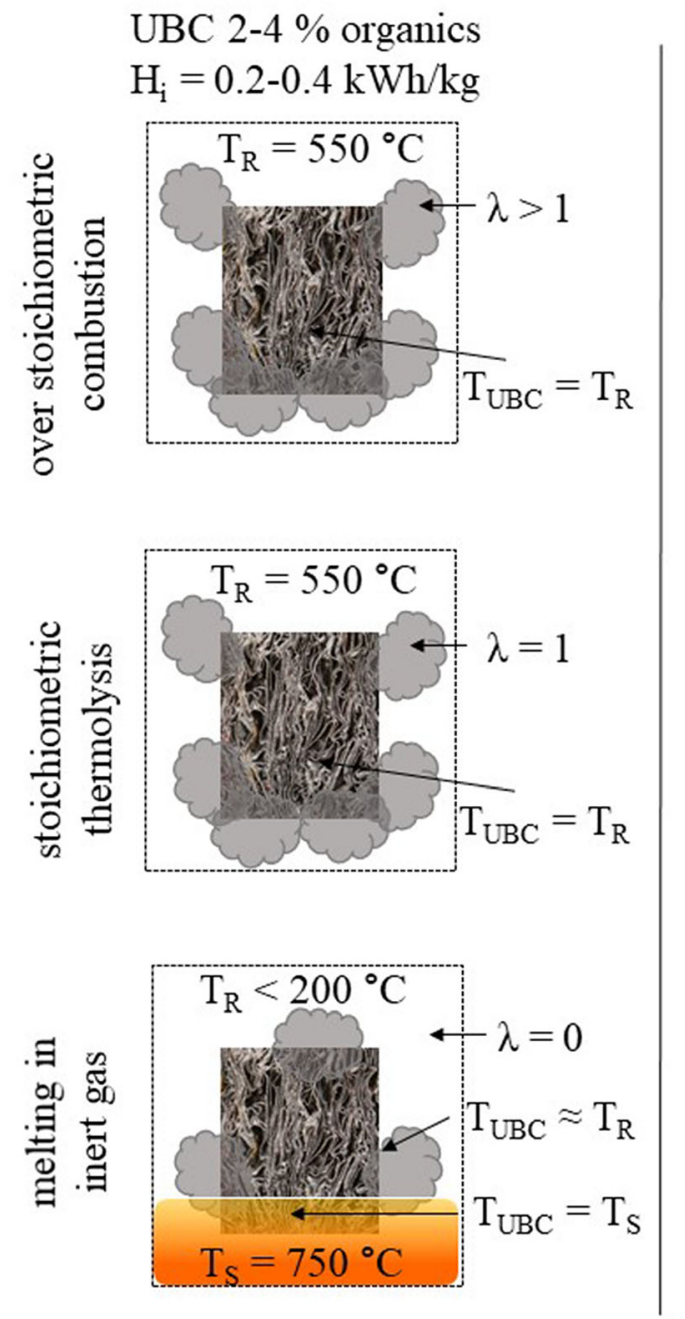

$$
\begin{gathered}
\text { UBC 8-12\% organics } \\
\mathrm{H}_{\mathrm{i}}=0.8-1.2 \mathrm{kWh} / \mathrm{kg}
\end{gathered}
$$
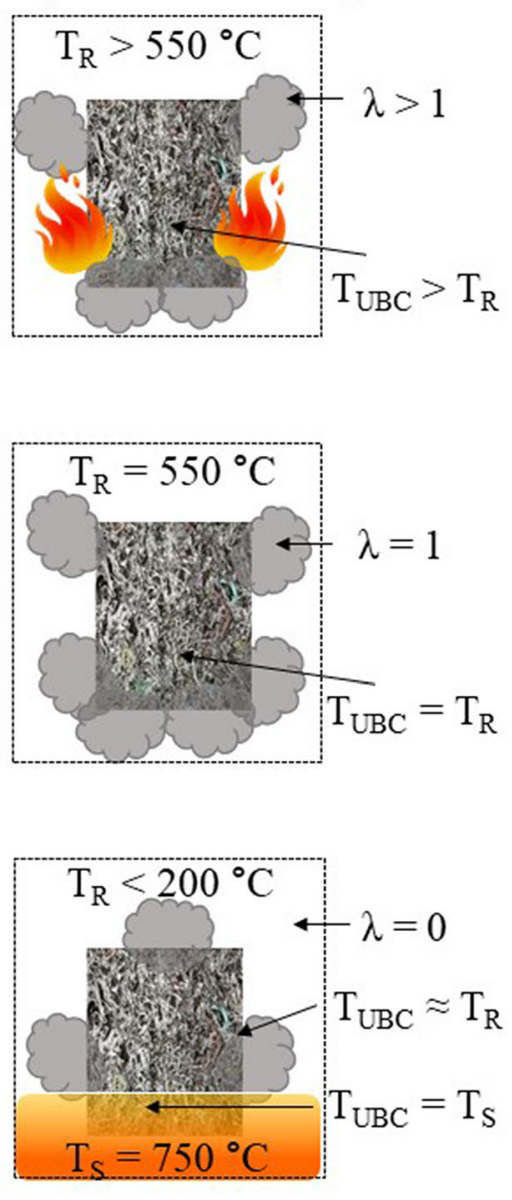

UBC $2-12 \%$ organics

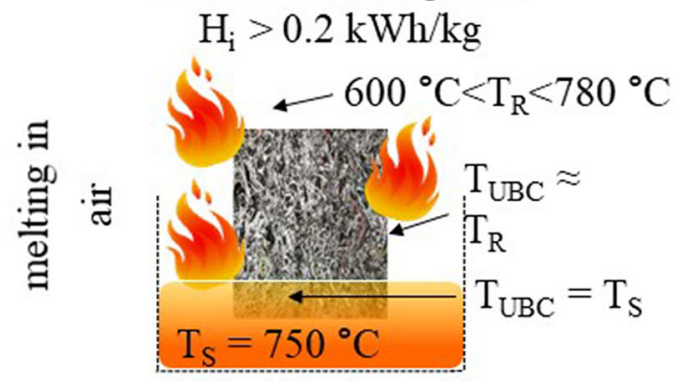

$\lambda=\quad$ total oxygen ration

$\mathrm{T}_{\mathrm{UBC}}=\mathrm{UBC}$ temperature

$T_{R}=$ reactor temperature

$\mathrm{T}_{\mathrm{S}}=$ melt temperature

$\mathrm{H}_{\mathrm{i}}=$ calorific value $\mathrm{UBC}$

$\Delta=$ organic combustion

$\xi=$ organic off-gas

Fig. 6. Conditions of organic removal from UBC scrap bales with different calorific values expressed as a simplified stationary process.

Finally, it is shown that the organic content of UBC scrap bales should be considered while calculating the $H_{i}$, which leads to metal oxidation in combination with oxygen-containing atmospheres in industrial furnaces. Metal oxidation is equal to metal loss and promotes $D$ by trapping liquid aluminum in the dross layer.

\section{ACKNOWLEDGEMENTS}

We would like to acknowledge TRIMET Aluminium SE for supporting this work. We also express our gratitude to Anne Kvithyld for her inspiration and motivation for this publication. 


\section{REFERENCES}

1. J.V. Koleske, Paint and Coating Testing Manual, 14th ed. of the Gardner-Sward handbook (Philadelphia: American Society for Testing \& Materials,1995), pp. 87-92.

2. D. Stoye, Paints, Coatings, and Solvents, 1st ed. (New York: Weinheim, 1993), p. 8.

3. A.P. Mouritz and A.G. Gibson, Fire Properties of Polymer Composite Materials (New York: Dordrecht, 2006), pp. 2257.

4. A. Kvithyld, J. Kaczorowski, and T. Abel Engh, Light Metals 2004, ed. A.T. Tabereaux (TMS, 2004), pp. 151-156.

5. M. Modigell, Grundlagen der Luftreinhaltung, 3rd ed. (Aachen, 2006), pp. 10-29.

6. S. Rumpel, Die autotherme Wirbelschichtpyrolyse zur Erzeugung heizwertreicher Stützbrennstoffe, Universität Karlsruhe (TH), Dissertation, 2000, p. 11.

7. J. Steglich, R. Dittrich, G. Rombach, M. Rosefort, B. Friedrich, and A. Pichat, Light Metals 2017, ed. A.P. Ratvik (Springer, 2017), pp. 1105-1112.
8. J. Campbell, Complete Casting Handbook: Metal Casting Processes, Techniques and Design (Oxford: ButterworthHeinemann, 2011), pp. 52-54.

9. J. Steglich, C. Matthies, M. Rosefort, and B. Friedrich, Light Metals 2018, ed. O. Martin (Springer, 2018), pp. 1123-1129.

10. F. Ostermann, Anwendungstechnologie Aluminium, 3rd ed. (Berlin: Springer, 2014), pp. 171-182.

11. H. Rossel, Light Metals 1990, ed. C.M. Bickert (TMS, 1990), pp. 721-729.

12. M. Schwalbe, World Metall. Erzmetall 64, 157 (2011).

13. J.H.L. van Linden, H.G. Reavis, Essential Read. Light Met. 165 (2013).

Publisher's Note Springer Nature remains neutral with regard to jurisdictional claims in published maps and institutional affiliations. 